\title{
MODELING THE IMPACT OF WATER WITHDRAWAL SCHEMES ON THE TRANSPORT OF PESTICIDES IN THE KOURIS DAM (CYPRUS)
}

\author{
S. $M A^{1, *}$ \\ S.C. KASSINOS ${ }^{1}$ \\ D.F. KASSINOS ${ }^{2}$ \\ E. AKYLAS ${ }^{1}$
}

${ }^{1}$ Dept. of Mechanical and Manufacturing Engineering,
University of Cyprus, 75 Kallipoleos St.,
P.O.Box 20537,Nicosia 1678, Cyprus
${ }^{2}$ Dept. of Civil and Environmental Engineering,
University of Cyprus, 75 Kallipoleos St.
P.O.Box 20537, Nicosia 1678, Cyprus

*to whom all correspondence should be addressed: e-mail: masw@ucy.ac.cy

\begin{abstract}
As part of an effort to understand the water quality dynamics in the Kouris Dam and the impact of possible management strategies, the present study assessed the transport process of atrazine in this reservoir and the effects of bottom and surface withdrawal schemes. The 2D laterally averaged CE-QUAL-W2 model was used in this study. It was found that, during the period of upstream river discharge, significant vertical variations of atrazine concentrations could be observed in the epilimnion. The maximum concentrations were found at the depth of $5-8 \mathrm{~m}$ rather than in the surface in this period. This suggests that the widely used assumption of complete mixing in the epilimnion is not valid for this period in this reservoir. It was also found that the dynamics of atrazine in the Kouris Dam were noticeably affected by the withdrawal schemes. Bottom withdrawal would significantly facilitate the transport of pesticides in this reservoir and therefore result in noticeably higher pesticide concentrations in deep layers. However, surface withdrawal is not able to lower atrazine concentrations in the epilimnion in this reservoir possibly due to the decreased mixing depth corresponding to the surface withdrawal, although more atrazine would be removed from the reservoir by the surface withdrawal. These results suggest that it is sensible to integrate withdrawal schemes into reservoir management system to achieve different water quality objectives under various scenarios.
\end{abstract}

KEYWORDS: pesticide, atrazine, transport, withdrawal, simulation, CE-QUAL-W2, Kouris Dam, stratification, deep reservoir

\section{INTRODUCTION}

In the last few decades, pesticide contamination in surface and ground water systems has emerged as one of the major threats to water supply and aquatic life in many countries and regions (Bays, 1970; Hashemy-Tonkabony and Gharibzadeh, 1979; Wynne, 1986; Shiraishi et al., 1988; Sudo et al., 2002; Kishimba et al., 2004; Konstantinou et al., 2006). In a large waterbody, such as a lake or a reservoir, this problem could be further complicated by the transport process of pesticides within the system. For deep reservoirs, the transport process of pesticides is usually affected by withdrawal locations and other factors (Kennedy, 1999). Understanding the major factors affecting the temporal and spatial variations of pesticide concentration in deep reservoirs, especially in response to the discharge of pesticides in the upstream rivers, is essential for water quality management. Some researchers simulated the transport of pesticides in shallow water bodies. For example, Mossman and Mulki (1996) simulated the transport process of four different pesticides in Coralville reservoir with a 1-D unsteady model and found that the reconstruction of boundary concentrations plays an important role in the accuracy of simulations (Mossman and Mulki, 1996). Benoist et al. (1998) developed the model BEKWAAM to predict heat balance, water quality and transport of 
pesticides in the reservoir. However, for deep reservoirs, the knowledge on the transport process of pesticides is still very limited and the impact of withdrawal schemes on the dynamics of pesticides has been rarely reported

Atrazine, (ATZ), 2-chloro-4-(ethylamine)-6-(isopropylamine)-s-triazine, is an s-triazine-ring herbicide that is used to stop pre and post emergence broadleaf and grassy weeds in major crops. It belongs to the group of substances (76 in total) that have been phased out in the EU under the Directive 91/414/EEC. However, a permit for limited extension of use on certain crops until the end of December 2007 has been allowed. Pesticides with essential uses have not been given EU-wide approval. Atrazine is also included in the list of the priority substances of the European Commission. In addition, environmental quality standards for atrazine have been proposed recently in respect to its concentrations in inland surface waters in the Proposal for a Directive on environmental quality standards in the field of water policy. Atrazine is one of the most frequently detected herbicides in surface and well water and contamination incidents have been reported all over the world. This is due to the fact that the triazine ring which is present in the molecular structure of the atrazine is strongly refractory. Therefore, atrazine was selected to be examined as a potential contaminant in Kouris Dam and in order to model the impact of bottom water withdrawal on the dynamics on its concentrations.

The purpose of this paper is to investigate the dynamic responses of atrazine concentrations in the Kouris Dam to the discharge of the upstream rivers and to assess the impact of the bottom withdrawals on the transport process. It is expected that the results of this study would advance the understanding of the transport process of pesticides and the impact of withdrawal schemes on the dynamics of atrazine in deep reservoirs.

\section{Study site}

Kouris Dam ( $\left.34^{\circ} 43^{\prime} \mathrm{N}, 32^{\circ} 55^{\prime} \mathrm{E}\right)$ impounds the deepest reservoir in Cyprus, the third largest island in the Mediterranean Sea (Figure 1). The maximum depth of this reservoir is $110 \mathrm{~m}$ and the corresponding capacity is 115 million $\mathrm{m}^{3}$. The catchment of the reservoir, a typical mountainous area with steep valleys, encompasses an area of $308 \mathrm{~km}^{2}$ with elevations from $150 \mathrm{~m}$ at the dam to $1850 \mathrm{~m}$ near Mountain Olympus.

There is a meteorological station (312-3746, Kouris Dam) set up for this reservoir near the dam. Because Cyprus has a typical Mediterranean climate with mild winters and hot, long and dry summers, about $80 \%$ of its annual precipitation falls from November to March. The inflow of the reservoir comes mainly from three tributaries: Kouris, Kryos, and Limnatis rivers. Since 1998 , additional water of about $12.87 \times 106 \mathrm{~m}^{3}$ per year $(1998-2005$, averaged) was transferred from another reservoir (Arminou) outside the catchment area via a $14.5 \mathrm{~km}$ long tunnel to this reservoir. The released water mainly serves three different purposes: irrigation, domestic water supply and downstream river recharge. The averaged monthly water inflow (including water transferred from Arminou dam since 1998) and outflow (withdrawal and evaporation, excluding leakages and seepages) are shown in Figure 2.

Kouris Dam plays an important role in the water supply of Cyprus because of the vagaries of the weather, which may result in a chronic water shortage in the island. It has been in function since 1989 and some hydrological, meteorological and water quality data have been archived. However, the dynamics of pesticides in the reservoir in response to the surface runoff of pesticides from entering upstream rivers are still unknown. In addition, currently water release (withdrawal) is through the near-bottom structure, and the impact of such withdrawals on the stratification, and therefore the transport of pesticides, in this dam has not been reported.

\section{THE NUMERICAL MODEL AND SIMULATION CONDITIONS}

The 2-D laterally averaged CE-QUAL-W2 model, which has been widely applied to stratified surface water systems such as lakes, reservoirs, and estuaries, was used in this study. It is a two-dimensional water quality and hydrodynamic FORTRAN code supported by the USACE Waterways Experiments Station and currently maintained by Portland State University. Water levels, horizontal and vertical velocities, temperature, and more than 20 other water quality 
parameters can be computed. The details of model structure, governing equations, numerical algorithms and validations were thoroughly discussed in the documentation of this model (Cole and Wells, 2005).

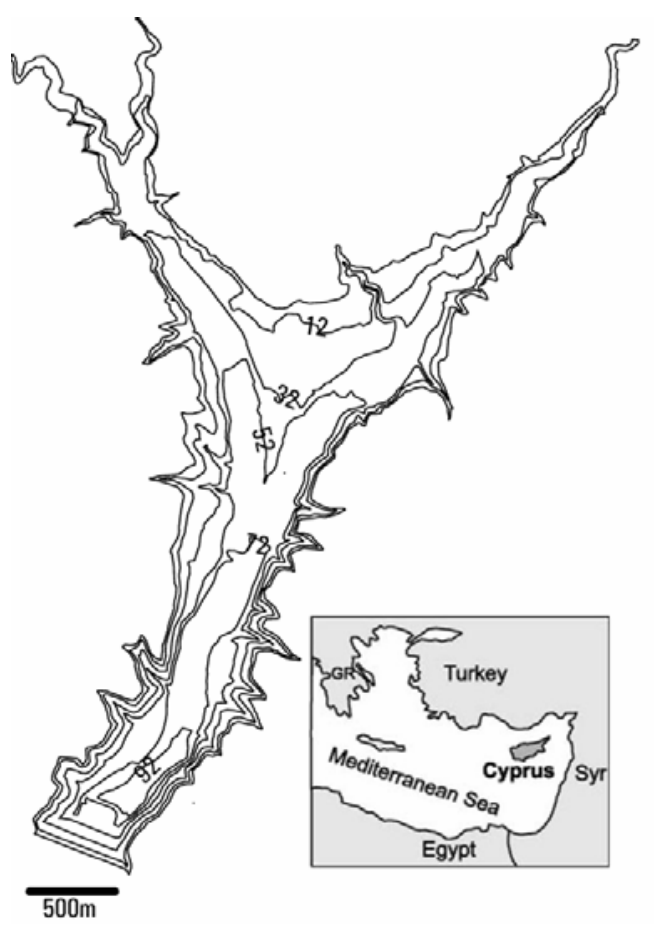

Figure 1. Bathymetry and location of Kouris Dam (based on the topographical map provided by Water Development Department)

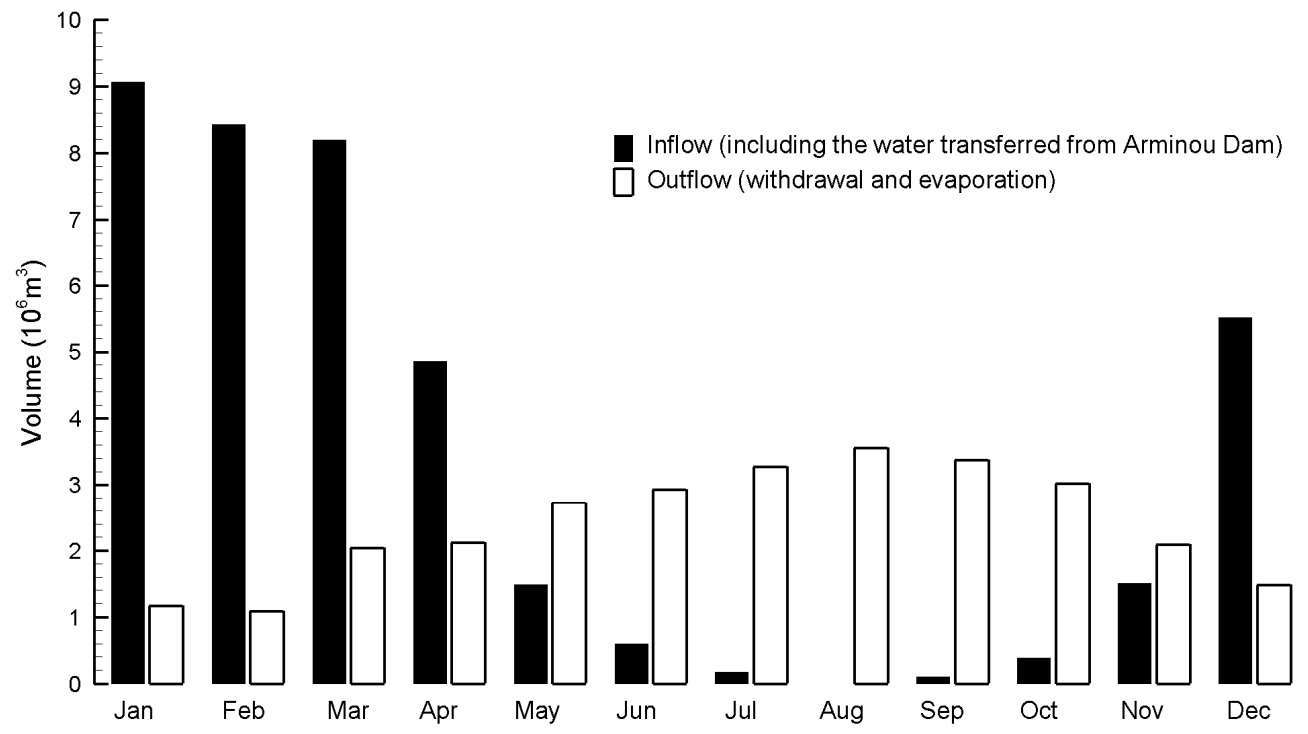

Figure 2. Averaged (1994-2005) monthly inflow and outflow of Kouris reservoir

For deep reservoirs and lakes, the CE-QUAL-W2 model has been widely used to study thermal stratifications, hydrodynamics and water quality under various geographical conditions (Kim et al., 1983; Garvey et al., 1998; Boegman et al., 2001; Deliman and Gerald, 2002; Kuo et al., 2006). Based on applications for more than 400 different waterbodies, with a wide variety of conditions, it has been found that the model is able to simulate water temperature, hydrodynamics and water quality accurately (Cole and Wells, 2005). 
In the simulations, the reservoir was divided into 52 segments longitudinally and 52 cells (layers) vertically. The depth of the layer varies from $2 \mathrm{~m}$ to $3 \mathrm{~m}$. The length of the segments varies from $150 \mathrm{~m}$ to $220 \mathrm{~m}$. Model calibration was conducted with the data of year 2005 . Daily meteorological data and monthly hydrological data were used. It was found the model is applicable to the Kouris Dam. Model application to Kouris Dam was discussed elsewhere (Ma et al., 2008).

To simulate the general patterns of the transport process of pesticides in this reservoir and the effects of different withdrawal schemes corresponding to the averaged conditions, 6hourly meteorological data of temperature, wind, humidity and evaporation of station 3123746 (Kouris Dam) and monthly hydrological data of the inflow, outflow, water level change, leakage and seepage were used in the simulations. The data from 1990 to 2005 were used to obtain the averaged meteorological conditions. The averaged hydrological data were derived from the data of the period from 1994 to 2005. The initial surface elevation of the reservoir was assumed at $240 \mathrm{~m}$ in all simulations. The monthly inflow and withdrawal are illustrated in Figure 2.

Because significant seasonal variations of stratification patterns in Kouris Dam were found in the study (Figure 3),[17] pesticides transport with spring-summer atrazine discharge (from Julian day 120 to 180) and autumn atrazine discharge (from Julian day 273 to 333) from upstream rivers were simulated separately. The concentration of atrazine in the inflow rivers was assumed as $20 \mathrm{\mu g} \mathrm{I}^{-1}$.

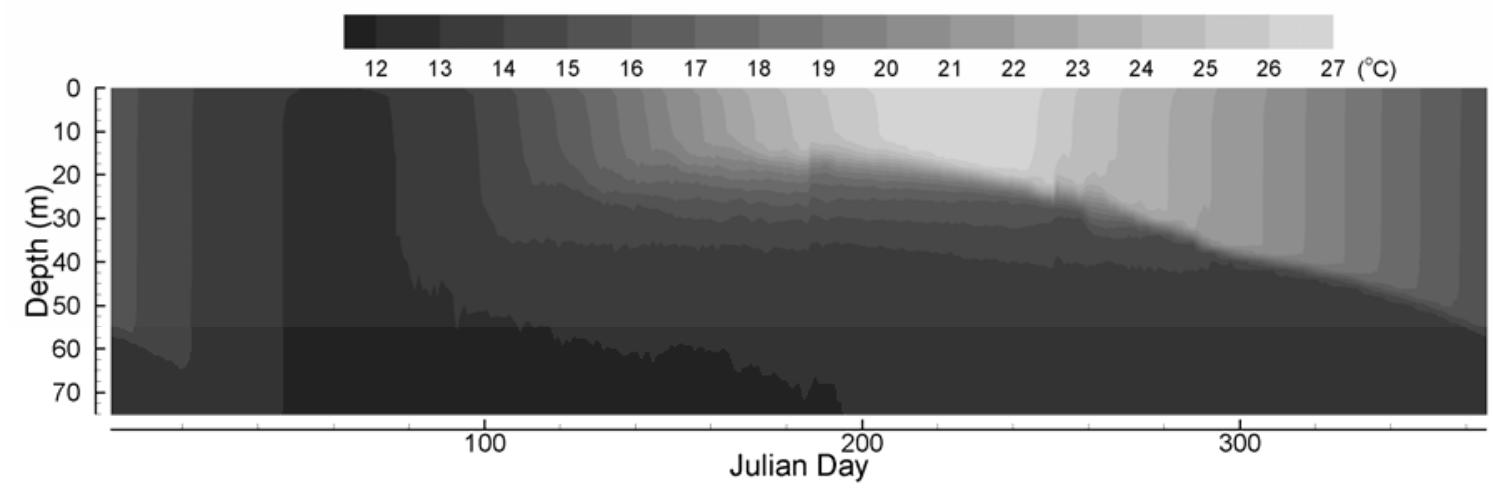

Figure 3. Seasonal variations of thermal stratification in Kouris Dam (conditions: bottom withdrawal; averaged meteorological and hydrological data)

\section{RESULTS AND DISCUSSION}

\subsection{Atrazine dynamics corresponding to different discharge seasons}

Figure 4 shows the downstream transport process of atrazine in surface layer with springsummer atrazine inflow. It was found that the response to the discharge of atrazine in the upstream rivers was observed about 4-5 days later in the dam (about 5.5km downstream of the upstream river). This suggests that the downstream transport rate of atrazine in Kouris Dam is about $1.2 \mathrm{~km} /$ day in the surface layer under the simulations conditions. Significant longitudinal gradient of atrazine in the surface layer was also observed during the discharging days in the upstream part (up to 2-2.5 km downstream of the inflow river) of the reservoir. Such longitudinal concentration differences are not significant in the far downstream regions of the reservoir. For example, as shown in Figure 4, on Julian day 125.5, the atrazine concentrations in surface layer are $4.7 \mathrm{\mu g} \mathrm{I}^{-1}$ and $0.125 \mathrm{\mu g} \mathrm{I}^{-1}$ in the locations of $800 \mathrm{~m}$ and $1600 \mathrm{~m}$ downstream of the inflow river respectively. The longitudinal concentration gradient is about $5.71 \mathrm{mg} \mathrm{I}^{-1}$ per $1 \mathrm{~km}$. Note that this gradient gradually decreases with time until the atrazine discharge stops because increased atrazine concentration in the downstream would gradually lower the longitudinal differences of atrazine concentrations. 


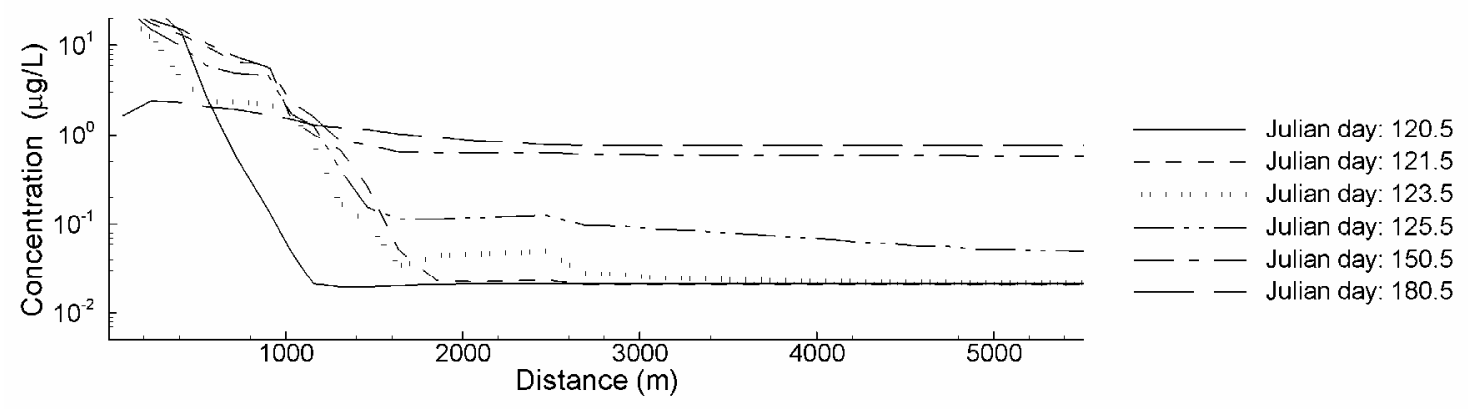

Figure 4. Downstream transport of atrazine (depth: 2m; spring-summer discharge)

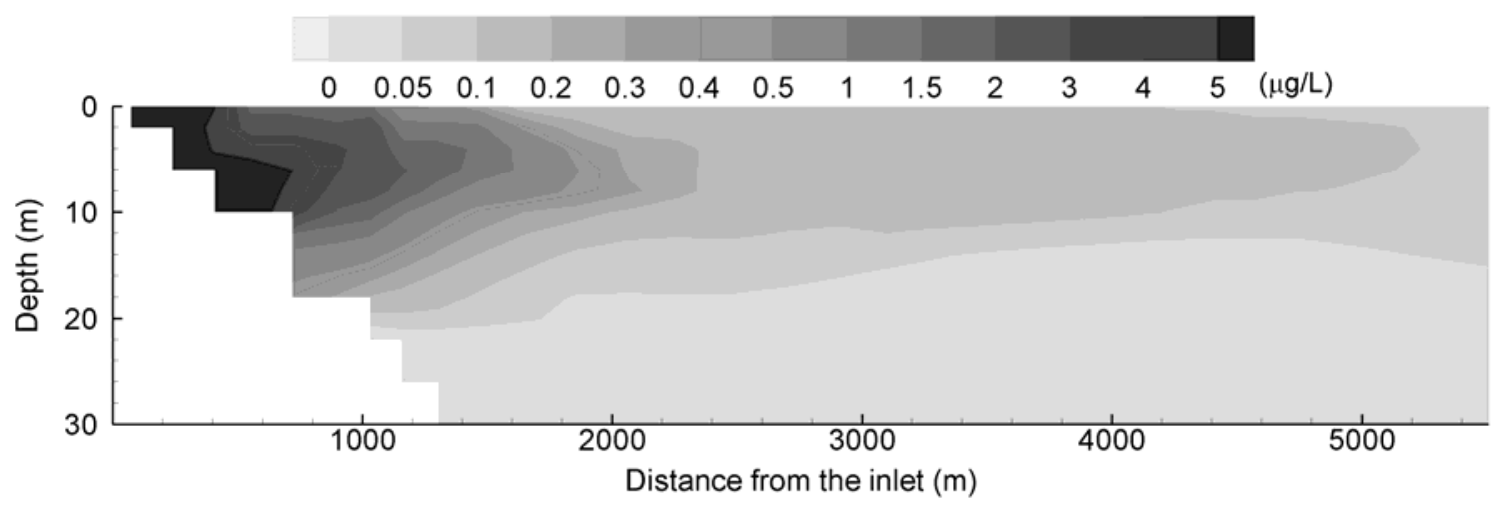

Figure 5. Concentration profile on Julian day 126.5 (spring-summer discharge)

It was found that during the period of upstream atrazine discharge, the maximum concentration in the epilimnion was observed in the layer with a depth around 5-8 meters. The differences of atrazine concentrations in epilimnion layer were remarkable as shown in Figure 5. For example, in Julian day 126.5, the maximum concentration in the water column at 1350 $\mathrm{m}$ downstream of the inflow river is $1.52 \mathrm{\mu g} \mathrm{I}^{-1}$, which was found at the depth of $5.5 \mathrm{~m}$; while at the surface, the concentration was only about $0.6 \mu \mathrm{g} \mathrm{I}^{-1}$. This suggests that the widely used assumption of complete mixing in the epilimnion is valid only for the period when the upstream discharge is not significant. When the discharge stops, the differences of concentrations in epilimnion would be negligible as shown in Figure 6. Note that these vertical variations of atrazine concentrations become less significant in far downstream of the reservoir. Figure 6 also indicates that atrazine concentrations in hypolimnion are significantly lower than that in epilimnion and sharp gradient can be found in the metalimnion. This suggests that the bottom withdrawal is unable to cause mixing of atrazine in the whole water column in Kouris Dam under the simulation conditions due to the stratifications as shown in Figure 3 . This implies that the stratification may buffer the impacts of pollution accidents on the released water.

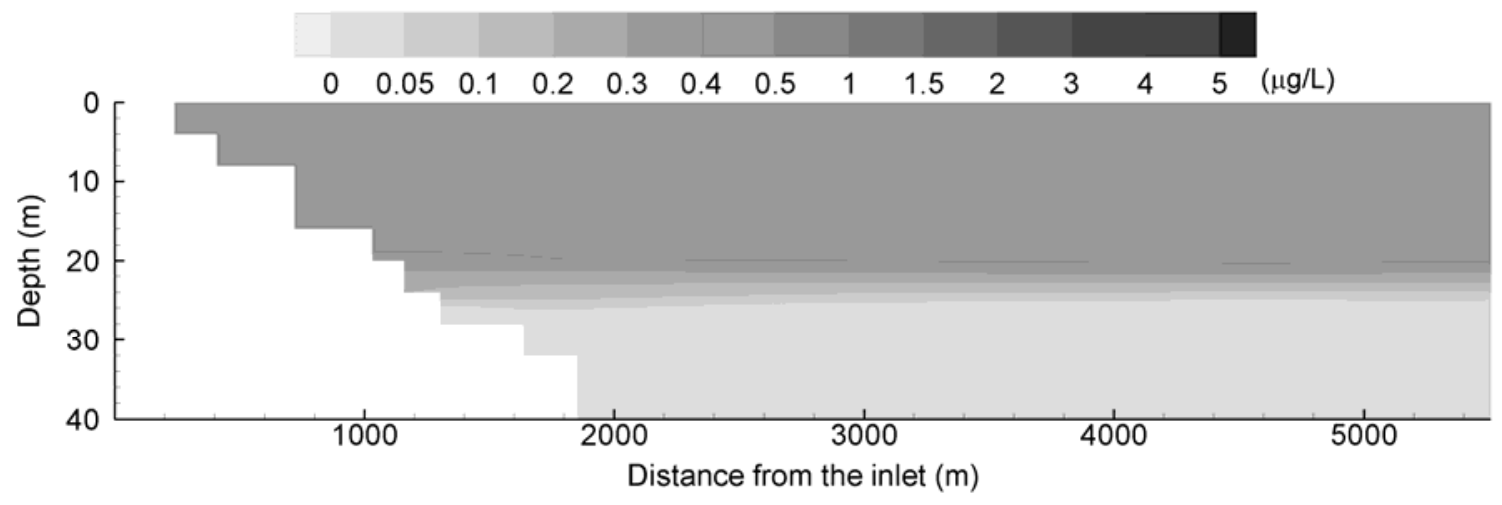

Figure 6. Concentration profile on Julian day 235.5 (spring-summer discharge) 


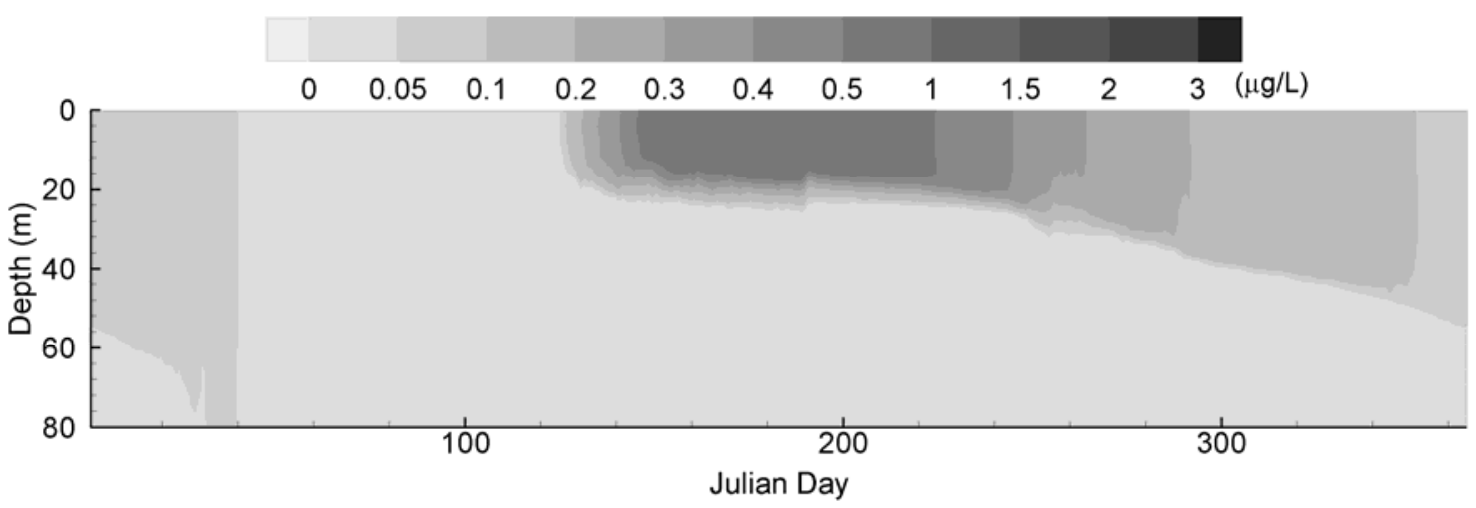

Figure 7. Seasonal variations of concentration profiles near the dam (spring-summer discharge)

Figure 7 shows the seasonal variations of atrazine concentrations in segment 32 (near the dam, about $5.4 \mathrm{~km}$ downstream of the inflow river) in one calendar year corresponding to the spring-summer discharge. It was found that seasonal variations of the vertical concentration profile in the water column share similar patterns with that of thermal stratification (Figure 4). This indicates that thermal stratification plays a very important role in the dynamics of pesticides in deep reservoirs.

For the autumn atrazine discharge, it was found that the transport process in the reservoir is noticeably different from that of spring-summer discharge. Figure 8 shows the concentration profile in the reservoir in Julian day 279.5 (6 days after the initial discharge). Compared to spring-summer discharge (Figure 5), for autumn discharge a noticeable deeper mixing was observed. For example, for autumn discharge, after 6 days of the initial discharge of the upstream rivers, the responses were observed at the depth of $27 \mathrm{~m}$ (Figure 8); while for spring-summer discharge, this depth was only $20 \mathrm{~m}$ (Figure 5 ). This is very likely caused the deeper epilimnion in autumn as shown in Figure 4. In addition, in autumn, the water temperature in river drops faster than that in the reservoir. This may also facilitate the transport of atrazine in the vertical direction.

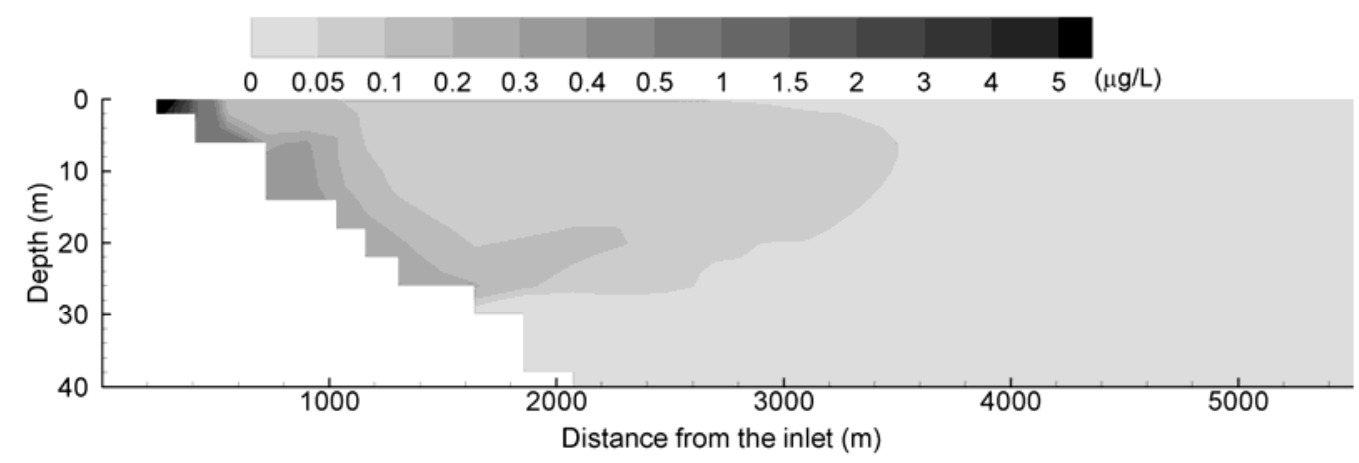

Figure 8. Concentration profile on Julian day 279.5 (autumn discharge)

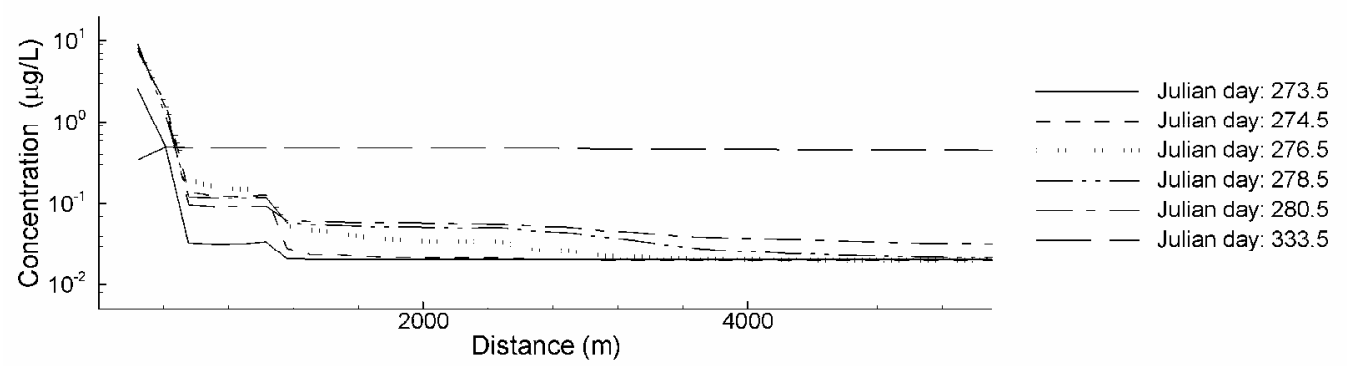

Figure 9. Downstream transport of atrazine (depth: $2 \mathrm{~m}$; autumn discharge) 
The downstream transport process of atrazine in surface layer with autumn atrazine discharge is shown in Figure 9. It was found that the responses to the upstream river discharge can be observed after about 7 days of the initial discharge. This suggests for autumn discharge the downstream transport is noticeably slower than that for spring-summer discharge. This is very likely related to the facilitated vertical transport in autumn in the reservoir corresponding to the deepened epilimnetic layer in this season.

\subsection{The impact of the withdrawal locations}

Currently, water is released via the near-bottom structure in Kouris Dam. To investigate the role of this bottom withdrawal on the dynamics of the pesticides in this reservoir, simulations were further conducted by assuming the withdrawal was taken place near the surface. Other simulation conditions were kept identical.

It was found that in the epilimnion, the withdrawal schemes did not have significant impacts on the overall transport process of the atrazine in this reservoir. However, during the period when atrazine is discharged from the upstream rivers, noticeable higher atrazine concentrations were observed for the case with surface withdrawal than the case with bottom withdrawal as shown in Figure 10. For example, at the depth of $2 \mathrm{~m}$, on Julian day 164 , atrazine concentration at segment 31 (near the dam) corresponding to surface withdrawal is about $0.77 \mu \mathrm{g} \mathrm{I}^{-1}$, which is about $5.3 \%$ higher than that corresponding to the bottom withdrawal. This suggests that although for surface withdrawal, the amount of atrazine removed from the reservoir is significantly larger than that for bottom withdrawal during the upstream discharge periods because of the higher atrazine concentrations in epilimnion than that in hypolimnion, surface withdrawal is not able to reduce the atrazine concentration in epilimnetic layer noticeably. This is mainly caused by the decreased thickness of the mixing layer corresponding to the surface withdrawal. When the epilimnion is thinner, the concentration of atrazine in this layer tends to increase. This also suggests that compared with the increased amount of withdrawals of atrazine, the effects of thermal stratification on atrazine concentration in the mixing layer is more pronounced.

However, in deeper layers, it was found that the bottom withdrawal may result in significant higher atrazine concentrations than the surface withdrawal for both spring-summer and autumn discharges. For example, as shown in Figure 10, for the spring-summer discharge, on Julian day 178 , bottom withdrawal results in about $53 \%$ higher atrazine concentrations at depth of $20 \mathrm{~m}$ than surface withdrawal; while on Julian day 215 , this value increases to $135 \%$. This implies that bottom withdrawal would significantly facilitate the downward transport of pesticides. So, In case of possible atrazine pollution accidents in the upstream of this reservoir, epilimnetic withdrawal should be used immediately if the main objective is to reduce the accumulation of atrazine in the reservoir system; however, if the main objective is to minimize the effects of atrazine on downstream water supplies, near-bottom hypolimnetic withdrawal may be considered so that there are some time to implement some restoration techniques in the reservoir.

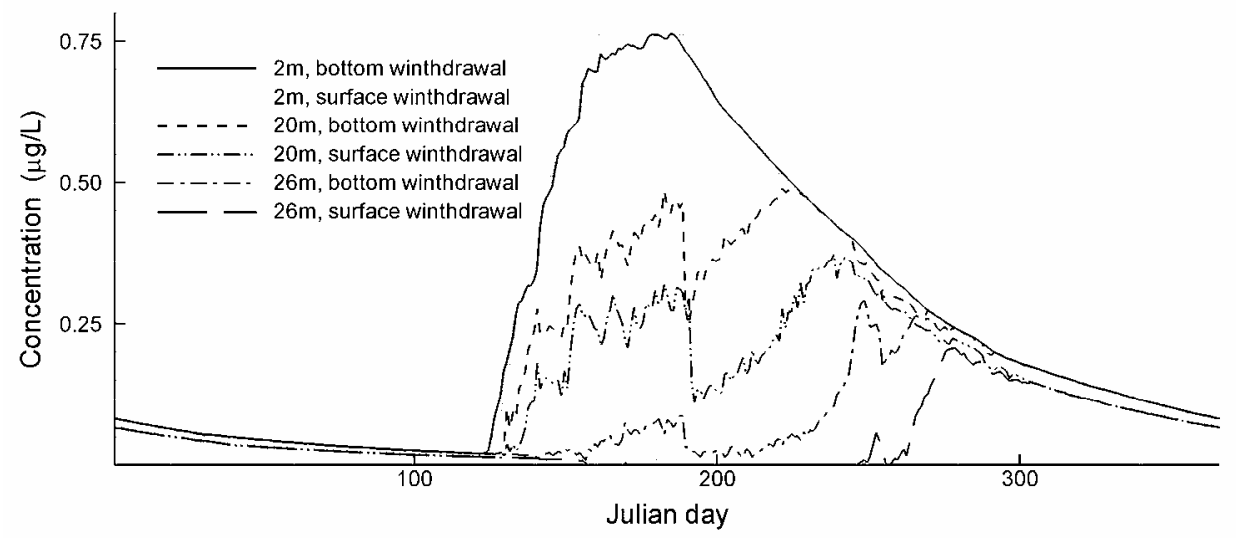

Figure 10. Comparison of atrazine concentrations with bottom and surface withdrawal at different depths (spring-summer discharge) 


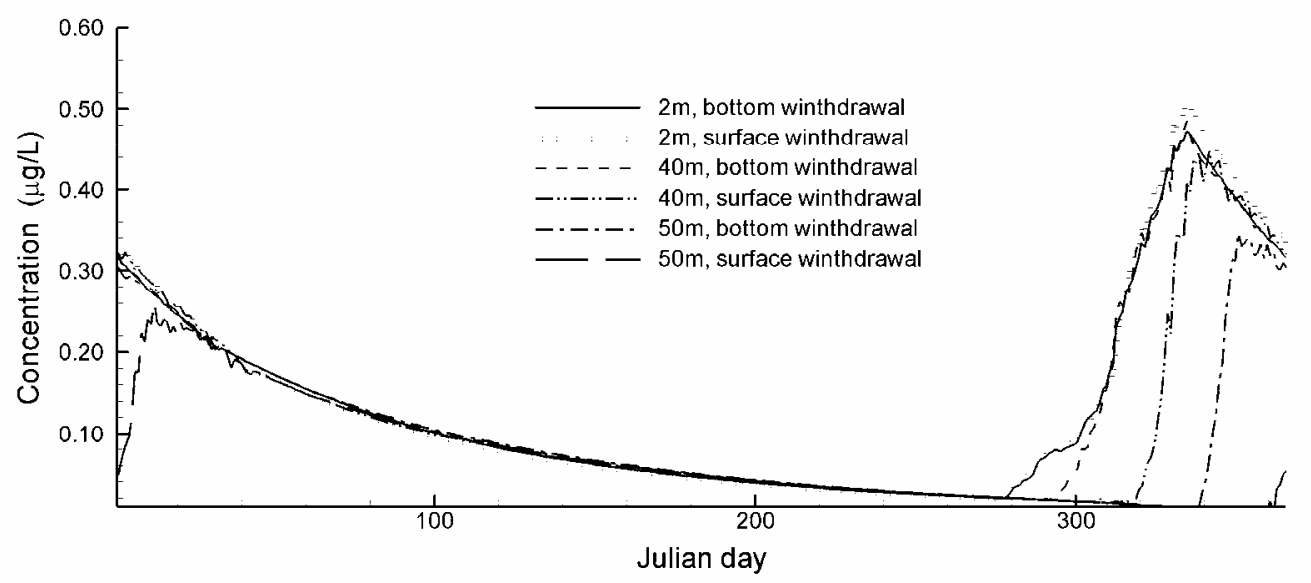

Figure 11. Comparison of atrazine concentrations with bottom and surface withdrawal at different depths (autumn discharge)

In addition, surface water withdrawal leads to a significant time lag of the concentration responses in deep layers to the upstream river discharges. For example, in the layer with a depth of $26 \mathrm{~m}$, with spring-summer discharge, for surface water withdrawal, the response of atrazine concentration in segment 31 (near the dam) to the discharge in upstream rivers was observed at the Julian day of 248 , which is about 85 days later than that for bottom withdrawal. With the autumn discharge (as shown in Figure 11), this lag in the response at the depth of $40 \mathrm{~m}$, is about 25 days. Note that for autumn discharge, the effects of withdrawal locations on the transport of atrazine were observed mainly at relatively deeper layers because of the increased thickness of the epilimnion layer in autumn and winter,

\section{CONCLUSIONS}

In deep reservoirs, withdrawal location (depth) may significantly affect the transport of the pollutants in the system. In this paper, the dynamics of atrazine in the Kouris Dam was simulated with the well-established CE-QUAL-W2 model and the impact of withdrawal schemes was studied. It was found that during the period of upstream river discharge significant vertical variations of atrazine concentrations exist in the epilimnion with the maximum concentrations at the depth of $5-8 \mathrm{~m}$ in the upstream part of the reservoir. This suggests that the widely used assumption of complete mixing in the epilimnion is not valid for this period. Compared with the spring-summer river discharge, slower downstream transport was found corresponding to autumn discharge possibly due to the increased downward transport in autumn. It was also found that bottom withdrawal would significantly facilitate the transport of pesticides in this reservoir and result in noticeably higher pesticide concentrations in deep layers. However, surface withdrawal is not able to lower atrazine concentrations in the epilimnion possibly due to the decreased mixing depth, although more atrazine would be removed from the reservoir by the surface withdrawal. These results suggest that it is sensible to integrate withdrawal schemes into reservoir management system to achieve different water quality objectives under various scenarios.

\section{ACKNOWLEDGEMENTS}

This work has been performed under the UCY-CompSci project, a Marie Curie Transfer of Knowledge (TOK-DEV) grant (contract No. MTKD-CT-2004-014199), and under the SBMEuroFlows project, a Marie Curie IRG grant (contract No. MIRG-CT-2004-511097) both funded by the CEC under the 6th Framework Program. Topographic, hydrological and meteorological data were provided by Water Development Department and Meteorological Services of Cyprus. We would like to thank Stefanos Papatryfonos, Kyriakos Kyrou, Andreas Christodoulidis, Vasoula Siamarou and Stelios Pashiardis for their suggestions and help in data preparation. 


\section{REFERENCES}

1. Bays L.R. (1970) 'Pesticide pollution and the effects on the biota of chew valley lake', Environmental Pollution, 1, 205-234.

2. Benoist A.P., Brinkman A.G., van Diepenbeek P.M.J.A. and Waals J.M.J. (1998) 'Bekwaam, a model fit for reservoir design and management', Water Science and Technology, 37, 269-276.

3. Boegman L., Loewen M. R., Hamblin P.F. and Culver D.A. (2001) Application of a twodimensional hydrodynamic reservoir model to Lake Erie. Canadian Journal of Fisheries and Aquatic Sciences. 58, 858-869.

4. Cole T.M. and Wells S.A. (2005) 'CE-QUAL-W2: A Two-dimensional, Laterally Averaged, Hydrodynamics and Water Quality Model, Version 3.2'. U.S. Army Engineers Waterways Experiment Station, Tech. Report EL-95-1. Vicksburg, M.S.

5. Deliman P.N. and Gerald J.A. (2002) Application of the Two-Dimensional Hydrothermal and Water Quality Model, CE-QUAL-W2, to the Chesapeake Bay - Conowingo Reservoir. Journal of Lake and Reservoir Management. 18, 1-9.

6. Garvey E., Tobiason J.E., Hayes M., Wolfram E., Reckhow D.A. and Male J.W. (1998) Coliform transport in a pristine reservoir: modeling and field studies. Water Science and Technology. 37, 137-144.

7. Hashemy-Tonkabony S.E. and Gharibzadeh M. (1979) 'Detection and determination of chlorinated pesticide residues in fish from Tehran reservoirs', Environmental Research, 18, 276-280.

8. Kennedy R.H. (1999) 'Reservoir design and operation: limnological implications and management opportunities'. In: Theoretical Reseervoir Ecology and Its Applications (eds Tundishi J.G. and Straskraba M.) pp. 1-28. Backhuys Publishers, the Netherlands

9. Kim B.R., Higgins J.M. and Bruggink D.J. (1983) Reservoir circulation patterns and water quality. Journal of Environmental Engineering, ASCE. 109, 1284-1294.

10. Kishimba M.A., Henry L., Mwevura H., Mmochi A.J., Mihale M. and Hellar H. (2004) 'The status of pesticide pollution in Tanzania', Talanta, 64, 48-53.

11. Konstantinou I.K., Hela D.G. and Albanis T.A. (2006) 'The status of pesticide pollution in surface waters (rivers and lakes) of Greece. Part I. Review on occurrence and levels', Environmental Pollution, 141, 555-570.

12. Kuo J.T., Lung W.S. , Yang C.P., Liu W.C., Yang M.D. and Tang T.S. (2006) Eutrophication modeling of reservoir in Taiwan, Environmental Modeling \& Software, 21, 829-844

13. Ma S., Kassinos S.C., Fatta D. and Akylas E. (2008), Effects of selective withdrawal schemes on thermal stratification in Kouris Dam (Cyprus), Lakes \& Reservoirs: Research and Management, 13, 51-61.

14. Mossman D.J. and Mulki N.A. (1996) 'One-dimensional unsteady flow and unsteady pesticide transport in a reservoir', Ecological Modelling, 89, 259-267.

15. Shiraishi H., Pula F., Otsuki A. and Iwakuma T. (1988), 'Behaviour of pesticides in Lake Kasumugaura, Japan', The Science of the Total Environment, 72, 29-42.

16. Sudo M., Kunimatsu T. and Okubo T. (2002) 'Concentration and loading of pesticide residues in Lake Biwa basin (Japan)', Water Research, 36, 315-329.

17. Wynne D. (1986) 'The potential impact of pesticides on the Kinneret and its watershed, over the period 1980-1984', Environmental Pollution Series A, Ecological and Biological, 42, 373386. 